\title{
MANEJO INTEGRADO DE PRAGAS EM MACIEIRA NO RIO GRANDE DO SUL II. USO DE Neoseiulus californicus PARA O CONTROLE DE Panonychus ulmi ${ }^{1}$
}

\author{
LINO B. MONTEIRO²
}

\begin{abstract}
RESUMO - Com o objetivo de implementar o controle biológico de ácaro-vermelho Panonychus ulmi em macieira foi proposta uma estratégia de controle baseada na criação de Neoseiulus californicus em estufa, em liberações inundativas e no uso de acaricidas, em um pomar comercial de macieira da Rincão das Flores Agropastoril (Agriflor), em Vacaria, Rio Grande do Sul, entre 1992 e 1996. A amostragem do ácaro-vermelho orientou as liberações e as transferências de ácaros predadores, das estufas de criação e dos ramos provenientes da poda verde, para parcelas de alta incidência de ácaro-vermelho. A eficiência da estratégia de controle do ácarovermelho foi avaliada com o levantamento de ovos de inverno. No primeiro ano, a associação de acaricidas com ácaros predadores permitiu um reduzido número de ovos de inverno do ácaro-vermelho, em torno de 1,3 ovo por unidade de amostragem contra 59,8 ovos na testemunha. No segundo ano, $58 \%$ das macieiras não foram pulverizadas com acaricidas. Nos dois anos subseqüentes, o controle do ácaro-vermelho foi realizado exclusivamente com ácaros predadores. $N$. californicus passou o inverno nas ervas daninhas do pomar e migrou espontaneamente para a copa das macieiras nos anos subseqüentes a sua introdução.
\end{abstract}

Termos para indexação: fitoseídeos, macieira, ácaro-vermelho, controle biológico, criação.

\section{APPLE INTEGRATED PEST MANAGEMENT IN RIO GRANDE DO SUL: II. THE USE OF The Neoseiulus californicus FOR CONTROL OF THE Panonychus ulmi}

\begin{abstract}
Having the purpose to increment the biological control of European red mites Panonychus ulmi in apple tree, a control strategy was proposed based on phytoseids Neoseiulus californicus in a greenhouse, on successive inoculative releases and use of acaricides, in a commercial apple orchard of Rincão das Flores Agropastoril (Agriflor), in Vacaria, Rio Grande do Sul, Brazil, among 19921996. The red mite samples guided both phytoseid releasing and transfering from the greenhouse and unwanted branches pruned, to apples trees with high population rates of European red mites. The inseticide effects on phytoseids were used to choose the pesticides for pest control. During the first winter season, the association between acaricides and phytoseids was able to reduce overwinter eggs, about 1,3 eggs/bud unit, while in the control area had 59,8 eggs. In the second year, the reduction of European red mite populations was significant. After the following two years, the control of European red mites was done only using the phytoseids. In the years that followed its introduction, $N$. californicus resurged on the apple trees.
\end{abstract}

Index terms: phytoseid, apple orchard, European red mites, biological control, mass rearing.

\section{INTRODUÇÃO}

O ácaro-vermelho Panonychus ulmi Koch (Acari: Tetranychidae) é considerado uma praga-chave da macieira no Sul do Brasil. O controle biológico é uma das estratégias para o controle desse ácaro (Mathy \& Baggiolini, 1967; Baggiolini \& Guignard, 1969; McMurtry et al., 1970; Fauvel \& Atger, 1981), a partir da introdução de ácaros predadores da família Phytoseiidae (Croft \& Hoyt, 1983). A adaptação desses inimigos naturais ao novo agroecossistema é uma exigência do controle biológico, verificada pelos reaparecimentos espontâneos nos anos seguintes à introdução (Rosen \& Huffaker, 1982). Para o sucesso do controle biológico, o ácaro predador deve ser tolerante às mudanças climáticas e sincronizar sua ocorrência com a da praga; além disso, as pragas-chave precisam ser manejadas com agroquímicos seletivos, sem os quais, ocorrem reduções de ácaros predadores (Baggiolini \& Guignard, 1969; Bostanian \& Coulombe,
1986; Monteiro, 1993). Os efeitos negativos do clima e das práticas fitossanitárias sobre os fitoseídeos podem ser compensados com a sua multiplicação e liberações inoculativas ou inundativas, proporcionando a manutenção desses inimigos naturais em densidade suficiente para limitar o desenvolvimento de ácaros fitófagos (Hoy, 1976).

Em Vacaria (RS), Anastrepha fraterculus (Wied) (Diptera: Tephritidae) é a espécie dominante de mosca-das-frutas na região, com frequiência de $96 \%$ das capturas em frascos caça-moscas (Salles \& Kovaleski, 1990a). Muitos dos agroquímicos recomendados (Bleicher, 1982; Salles \& Kovaleski, 1990b; Salles, 1991) para o controle desse díptero são extremamente tóxicos para ácaros predadores (Besson et al., 1978; Service de la Protection des Végétaux, 1983; Association Nationale pour la Protection des Plantes, 1987). A presença de outras pragas, como Grapholita molesta (Busck.) (Lepidoptera: Tortricidae) e Naupactus sp. (Coleoptera: Curculionidae), cujos conhecimentos bioecológicos

1 (Trabalho 129/2001). Recebido: 02/07/2001. Aceito para publicação: 22/02/2002.

2 Eng. $^{\circ}$ Agrônomo, D. Sc., Professor do DFF/UFPR, Rua dos Funcionários, 1540, Caixa Postal 19.061, CEP 81531-990, Curitiba, PR, lbmonteiro@mais.sul.com.br 
na região não foram devidamente aprofundados, conduzem aos tratamentos preventivos, levando à seleção de indivíduos resistentes aos agroquímicos e provocando desequilíbrio entre as espécies de fitófagos e inimigos naturais.

O objetivo deste trabalho foi definir uma estratégia de controle do ácaro-vermelho da macieira, associando o controle biológico com o controle químico, por meio da multiplicação e de liberação inundativa de Neoseiulus californicus McGregor (Acari: Phytoseiidae) e da seleção de inseticidas menos tóxicos aos ácaros predadores.

\section{MATERIALEMÉTODOS}

Área experimental - O presente estudo foi realizado entre outubro de 1992 e fevereiro de 1996, em um pomar comercial de macieiras da empresa Rincão das Flores Agropastoril, localizada no município de Vacaria, Rio Grande do Sul. O pomar situa-se no km 32 da BR 285, distante $10 \mathrm{~km}$ do pomar mais próximo. A área de plantio foi de 229,1 ha, dividida em 6 parcelas de macieiras, as quais foram subdivididas em quadras, plantadas com as variedades Gala e Fuji (Tabela 1). No primeiro ciclo vegetativo (1992-93), duas quadras de macieiras, com 2 ha cada, foram utilizadas como testemunhas, sendo uma da variedade Gala (Gala $\left.{ }_{\text {testemunha }}\right)$, localizada na parcela III, e a outra de Fuji (Fuji $\left.{ }_{\text {testemunha }}\right)$, pertencente à parcela $\mathrm{V}$, ambas não sofreram nenhum tratamento para o controle de ácaro-vermelho e não houve a liberação de ácaros predadores. Além dos tratamentos regulares, as testemunhas foram pulverizadas com deltametrina uma vez por mês, com o objetivo de evitar o desenvolvimento de ácaros predadores que porventura pudessem migrar para estas áreas; nos anos subseqüentes, não foi possível impedir a migração de ácaros predadores liberados no pomar para as quadras-testemunha.

Analisando o histórico fitossanitário do pomar (Tabela 2 ), verificou-se que as pragas mais importante nos ciclos vegetativos de 1989/90 e de 1990/91 foram: A. fraterculus, $P$. ulmi, G. molesta, Eriosoma lanigerum (Hausmann) (Hemiptera: Aphididae) e Naupactus sp. Os agroquímicos empregados para o controle dessas pragas foram: azinphos ethyl, clofentezine, deltametrina, diazinon, dimetoato, fenpropatrina, fenthion, malathion, phosmet, propargite, triclorfon e vamidothion.

Criação do ácaro predador em estufa - Em 1992, fêmeas do fitoseídeo N. californicus foram obtidas do Centro Nacional de Pesquisa do Meio Ambiente (CNPMA), unidade da Empresa Brasileira de Pesquisa Agropecuária (EMBRAPA), em Jaguariúna-SP, as quais foram originárias do Peru. Os ácaros predadores foram criados no pomar experimental, em estufas de plástico, contendo oito salas de $12 \mathrm{~m}^{2}$, das quais, três foram destinadas à produção do ácaro predador e duas para o ácarorajado, Tetranychus urticae Koch (Acari: Tetranychidae), utilizado como alimento para o ácaro predador. Aproximadamente quinze sementes de feijão foram semeadas em cada pote de plástico de 20x15 cm; a capacidade média da sala foi de 300 potes, quantidade suficiente para assegurar a produção de $N$. californicus (Monteiro, 2001a). A produção média de $N$. californicus por pote, entre outubro e março, foi de 420 ninfas e adultos, não incluindo os ovos e as larvas. O intervalo de liberação foi de 4 a 7 dias, no período estival, enquanto, nos meses de abril a setembro, houve redução natural na produção de ácaros predadores e o intervalo médio entre as liberações foi de 25 dias. A diminuição da produção no inverno ocorreu devido à baixa temperatura interna das salas, pois o aquecimento com resistências de 900 watts/hora/sala não foi suficiente para compensar a perda de calor. As salas foram iluminadas por 4 lâmpadas fluorescentes de 40W.

Multiplicação de ácaros predadores no pomar - macieiras de porte vigorosos, em condições de serem podadas (poda verde), receberam as primeiras liberações de $N$. californicus. Essas foram conduzidas de modo a permitir que a população de $P$. ulmi fosse maior do que a tolerada pelo índice do nível de controle (NC), com a finalidade de aumentar a população do ácaro-vermelho, disponibilizando alimento suficiente para o desenvolvimento de várias gerações de $N$. californicus. À medida que P. ulmi foi reduzido pelo ácaro predador, as macieiras foram podadas e os seus ramos distribuídos em parcelas previamente selecionadas, visando a introduzir ou aumentar a população de $N$. californicus (Blommers, 1989). Foram transferidos materiais vegetativos de uma área equivalente a, aproximadamente, 12 ha nos ciclos vegetativos de 1992/1993 e 1993/1994. A estimativa do número de ácaros predadores distribuídos na poda verde foi calculada pela multiplicação do número médio de folhas por ramo (10 folhas), de ácaros predadores por folha (4 a 7 indivíduos), de ramos-ladrão retirados por macieira (média de 5 ramos), de macieiras por hectare (média de 1500 plantas) e do número de hectares em que foi realizada a poda verde.

Liberação dos ácaros predadores - Os ácaros predadores foram liberados sobre as macieiras junto com as folhas de feijoeiros e ácaros-rajados. Utilizaram-se em torno de 250 potes para cada liberação, aproximadamente 105.000 ninfas e adultos. A quantidade de material depositado por hectare foi proporcional à massa foliar das macieiras e à porcentagem de presença do ácarovermelho, a qual foi previamente determinada pelo monitoramento. Os adultos levaram de 12 a 24 horas para migrarem das folhas de feijoeiros para as macieiras, enquanto as larvas permaneceram nas folhas dos feijoeiros por mais tempo. As parcelas de Gala e Fuji receberem N. californicus a partir de outubro de 1992, priorizando àquelas que apresentaram $30 \%$ de folhas com presença de $P$. ulmi. Normalmente, as liberações foram realizadas entre 8 e 12 horas e 16 e 18 horas, evitando os dias chuvosos; sempre que possível, a liberação ocorreu no período da tarde, pois as folhas do feijoeiro permanecem mais tempo túrgidas e abertas, o que facilita a passagem do ácaro predador para as macieiras (Monteiro, informação pessoal).

A partir da primavera de 1993, as liberações de ácaros predadores foram realizadas prioritariamente de acordo com os resultados da amostragem de ovos de inverno. No verão, os monitoramentos de folhas identificaram as áreas para liberação, cuja distribuição foi total ou parcial. Por meio da poda verde, os ácaros predadores foram distribuídos no pomar, depositando de dois a três ramos por macieira, em posição transversal à linha de plantio e à altura de $1,6 \mathrm{~m}$.

Monitoramento das formas móveis de ácaros - Durante os 4 anos do estudo, os levantamentos dos ácaros foram realizados segundo a metodologia Baillod \& Schlaepler (1982) e Baillod (1989), baseada na presença e ausência de ácaros sobre as folhas. Foram coletadas de 40 a 60 folhas por ha, localizadas em ramos do ano, a 1,70 $\mathrm{m}$ de altura e na periferia média da copa. A amostragem foi realizada em 3 a 4 filas por ha, dependendo do 
formato das parcelas, quantificando a porcentagem de ácaros em cada fila. A amostragem serviu para determinar a estimativa de risco imediato e potencial que, segundo Audemard et al. (1982), foi definida, respectivamente, como sendo: o nível obtido indica o limite máximo de infestação, além do qual exige intervenção imediata" e " determina o nível de previsão da infestação, estimado a partir de um estado precedente da fase nociva da praga". O NC foi de $40 \%$ de folhas com presença de $P$. ulmi, sendo que, em 1994/95 e 1995/96, o NC passou para 80\% de presença, à condição que houvesse $40 \%$ de $N$. californicus (Staübli et al., 1991), e que as macieiras não apresentassem o sintoma de bronzeamento generalizado.

Monitoramento de ovos de inverno do ácaro-vermelho - Os ácaros-vermelhos depositam ovos hibernantes em torno das gemas dos ramos das macieiras, o que possibilita o seu monitoramento. Com o auxílio de um estereomicroscópio (10 a 20 vezes), foram contados todos os ovos de inverno em torno de uma gema bem desenvolvida, inserida em ramos de dois anos de idade (Baillod, 1979). O número de ramos observados foi de 45 a 60 por hectare, distribuídos em 3 a 4 filas por quadra. Este monitoramento avalia a eficiência do manejo fitossanitário do ciclo anterior e estima o risco potencial de infestação de $P$. ulmi para a primavera seguinte. Nas duas primeiras avaliações, determinou-se o efeito do óleo mineral (Triona 4\%) sobre os ovos de inverno, realizando o monitoramento antes e depois da pulverização. O NC foi de 10 ovos por unidade de amostra (ramos de 1 cm) (Baillod, 1979).

Monitoramento de mosca-das-frutas - A. fraterculus foi monitorada com frasco caça-moscas do tipo McPhail, utilizando suco de uva a $25 \%$ e distribuídas 1 para cada 5 ha, em pontos de entrada da praga no pomar, previamente identificados. A leitura foi feita 2 vezes por semana. O NC foi de $0,5 \mathrm{mosca} / \mathrm{frasco} / \mathrm{dia}$. $\mathrm{O}$ monitoramento dos demais insetos baseou-se no método visual, sem uma metodologia específica, pois, neste pomar, A. fraterculus foi considerada a única praga-chave.

Seleção de agroquímicos - Para o ciclo 1992/93, os agroquímicos utilizados para o controle de insetos foram selecionados a partir de Salles \& Kovaleski (1990b) e Salles (1991). Entre 1993/94 e 1995/96, a escolha dos inseticidas foi baseada nos experimentos realizados em laboratório e no pomar (Monteiro, 1993; Monteiro, 2001b) (Tabela 2).

As populações de ácaros-vermelhos foram pulverizadas com acaricidas específicos ao alcançarem o NC. No primeiro ano, foram usados acaricidas do mercado e, a partir do segundo ano, selecionou-se propargite, em função de sua baixa toxicidade para a população de fitoseídeos, de acordo com Service de la Protection des Végétaux (1983) e Association Nationale pour la Protection des Plantes (1987). A quebra de dormência das macieiras foi feita com cianamida hidrogenada $(0,4 \%)+$ óleo mineral (Triona a $4 \%$ ), pulverizado a $1.000 \mathrm{l} / \mathrm{ha}$ com um turbopulverizador.

\section{RESULTADOS E DISCUSSÃO}

\section{Ciclo vegetativo de 1992/93.}

Outubro a dezembro - Os ácaros predadores foram distribuídos em 82,8 ha da variedade Gala (Tabela 3), cuja densidade média estimada foi de 13.569 indivíduos por hectare. A dispersão do predador entre as macieiras foi lenta, pois, na variedade Gala, a porcentagem média de folhas com a presença de $N$. californicus foi de $6,5 \%$ em 4 de janeiro (Figura 1-A). Na variedade Fuji, ácaros predadores foram liberados em 46,5 ha, na densidade estimada de 9.000 ácaros por hectare. Diferente do ocorrido em Gala, observou-se que os predadores se distribuíram mais eficientemente na massa foliar de Fuji, variando de 9,4 a 48,8\% de presença de N. californicus, em 4 de janeiro (Figura 1-B). Considerando que a densidade estimada de ácaros predadores liberados na Fuji foi menor do que na Gala, parece que a melhor distribuição de $N$. californicus nas parcelas de Fuji pode estar relacionada como o manejo das macieiras, cujas copas foliares foram abertas no inverno anterior ao início das liberações, retirando ramos mais vigorosos ou "ladrões". Esta é uma prática cultural que visa a obter frutos de qualidade e permite maior aeração da planta, o que pode ter facilitado, indiretamente, a dispersão de fitoseídeos durante as pulverizações com turbopulverizadores. $\mathrm{O}$ volume de ar produzido nestas turbinas equivale a $19,5 \mathrm{~m}^{3} / \mathrm{seg}$, sendo projetado violentamente na direção das plantas, à velocidade de 112 $\mathrm{km} / \mathrm{h}$ (modelo básico de Jacto 2000), podendo, assim, reproduzir o efeito que as correntes de ar têm sobre a dispersão de ácaros predadores (Hoy, 1982; Tixier et al., 1998).

Nestes três primeiros meses, foram distribuídos ácaros predadores em $55 \%$ do pomar; entretanto, não foi em quantidade suficiente para evitar altas porcentagens de presença de $P$. ulmi em certas quadras do pomar (Figura 2). Nas quadras onde foram liberados $N$. californicus, as pulverizações de acaricidas foram realizadas de forma parcial, limitando-as às fileiras com porcentagens de presença maiores do que o NC, permitindo que $N$. californicus manifestasse o seu potencial de predação e de crescimento, o que se verifica quando em altas densidades de presas (Huffaker et al., 1977; Fauvel, 1993); no restante do pomar, as pulverizações foram em área total (Tabela 4). Neste período, foram pulverizados o equivalente a 178,9 ha em Gala e a 62,3 ha em Fuji, o que corresponde, respectivamente, a $146,2 \%$ e a $58,4 \%$ da área plantada com cada variedade.

Observou-se que, nas parcelas de Gala, foi realizada 1,8 pulverização a mais do que na Fuji. Essa diferença reflete as dificuldades em realizar a estimativa de risco potencial de P. ulmi nas parcelas de Gala, após o monitoramento de 11 de dezembro, pois esta estimativa depende da capacidade de desenvolvimento da população de ácaro-vermelho e o período de carência das matérias ativas. Recomendou-se o controle químico em várias quadras de Gala, mesmo quando as populações de $P$. ulmi não tenham atingido o $\mathrm{NC}$, pois a ação do aumento da temperatura sobre o desenvolvimento do ácaro-vermelho poderia fazer com que estas populações ultrapassassem o NC nas primeiras semanas de janeiro, coincidindo com o período de carência dos acaricidas e impossibilitando o seu controle. Os acaricidas recomendados, propargite e clofentezine, possuem, respectivamente, 30 e 40 dias de carência (Andrei 1990); logo, a última pulverização em Gala não poderia ser realizada após 2 de janeiro. Esta recomendação ocorreu em quase todas as quadras onde não haviam sido liberados ácaros predadores.

Nas parcelas de Fuji, o uso de acaricidas foi menor, influenciado pelos seguintes motivos: 1) Controle químico de $P$. ulmi foi baseado na estimativa de risco imediato (NC), podendo ser realizado a qualquer momento; 2) A colheita de Fuji não coincide com o período mais favorável para o desenvolvimento do ácaro-vermelho (janeiro e fevereiro); 3) Melhor distribuição de 
N. californicus nas quadras (Figura 1-B); 4) Menor efeito de acaricidas sobre o desenvolvimento de ácaros predadores, em função da redução do número de pulverizações (Tabela 4); 5) Maior tolerância ao bronzeamento foliar em Fuji do que em Gala. Os danos provocados pela alimentação de ácaros fitófagos nas macieiras são influenciados pela intensidade de ataque, tolerância da planta e condições do clima (Huffaker et al., 1969).

Os inseticidas usados para o controle de A. fraterculus foram diferenciados nas parcelas com ou sem ácaros predadores. Nas parcelas onde foram liberados $N$. californicus, optou-se por phosmet, pois apresenta menor toxicidade para os fitoseídeos, segundo Besson et al. (1978), Service de la Protection des Végétaux (1983), Association Nationale pour la Protection des Plantes (1987) e Monteiro (1993) e Monteiro (2001 b, no prelo). Em 21-12-92 foi utilizado fenthion em ambas as variedades, sendo que as amostragens não revelaram reduções de ácaros predadores, imediatamente após a pulverização (Figuras 1-A, 1-B), exceção à Parcela V, contrariando os resultados de Monteiro (1993) e Monteiro (2001 b, no prelo).

Janeiro a abril - Neste período, foram produzidos, aproximadamente, 2.500.000 ácaros predadores na estufa que, juntamente com 6.300.000 N. californicus originados da poda verde, foram transferidos para novas quadras ou liberados em quadras que apresentaram baixa densidade de ácaro predador. Todas as parcelas de Gala e de Fuji receberam $N$. californicus ao final deste ciclo vegetativo (Tabela 3 ), sendo que as parcelas de Fuji continuaram tendo maior presença de ácaros predadores. Em 30-011993, verificou-se acentuada redução de P. ulmi (Figura 1-C, 1D), coincidindo com aumento da distribuição de $N$. californicus na massa foliar (Figura 1-A, 1-B), características observadas em um predador do tipo limpeza (Baillod, 1984), enquanto, nas quadras-testemunha (Gala ${ }_{\text {testemunha }}$ e Fuji ${ }_{\text {testemunha }}$ ), os ácaros-vermelhos desenvolveram-se sem limitações, provocando a queda de folhas em fevereiro (Figura 1-C, 1-D), demonstrando que, neste ano, não houve influência negativa do clima (Jeppson et al., 1975) sobre a flutuação de ácaros fitófagos. Assim, pode-se atribuir esta redução exclusivamente aos fitoseídeos e ao manejo de acaricida (44,3\% da área de Fuji).

A presença de $N$. californicus nas folhas de macieira diminuiu com a redução de $P$. ulmi, o que é normal, pois a dispersão de $N$. californicus está associada à capacidade de busca de novas presas, ocorrendo quando os níveis de $P$. ulmi forem baixos ou próximos ao ponto de equilíbrio entre ambas as populações (Baillod, 1984; Huffaker et al., 1977). N. californicus migrou para o solo entre março e abril, provavelmente à procura de abrigo e alimento (Figura 1), migração também observada por Fauvel (1993).

Embora os testes de toxicidade tenham revelado o efeito nocivo do fenthion sobre N. californicus (Monteiro, 1993; Monteiro, 2001 b, no prelo), a amostragem no pomar realizada em 4-01-1993 não mostrou acentuada redução na flutuação de $N$. californicus em função do fenthion aplicado em 21-12-92, provavelmente, porque houve tempo suficiente para a recuperação dos ácaros predadores neste intervalo. Somente os ácaros predadores da parcela $\mathrm{V}$, em Fuji, tiveram uma redução significativa após pulverização (Figura 1-B).

A amostragem de ovos de inverno nas seis parcelas, em ambas as variedades, realizadas antes da quebra de dormência, mostrou significativa redução de ovos hibernantes quando com- parados com as testemunhas Gala $a_{\text {testemunha }}$ e Fuji ${ }_{\text {testemunha }}$ (Tabela 5), as quais tiveram em média 43,2 vezes mais ovos de inverno do que as demais. A baixa taxa de ovos de inverno foi resultado da redução de fêmeas de $P$. ulmi entre fevereiro e abril (Figura 1-C, 1-D). O uso de óleo mineral para a quebra da dormência provocou redução média de $70 \%$ dos ovos hibernantes, diminuindo o risco potencial de infestação para o próximo ciclo; entretanto, este valor foi menor do que o encontrado por Reis Filho \& Petri (1992).

Ciclo vegetativo de 1993/94. A metodologia utilizada para levantamentos de ovos de inverno mostrou-se adequada, possibilitando identificar fileiras com maiores infestações de ovos hibernantes, o que permitiu pulverizações localizadas com o ovicida clofentezine, reduzindo o risco potencial de infestação na primavera (Degrange, 1987; Monteiro, 1994). Assim, a população hibernante de $P$. ulmi originou baixa porcentagem de formas móveis até novembro (Figura 3), tendências similares foram obtidas por De Busschère (1970) e Baillod et al. (1989).

A maior densidade do ácaro-vermelho coincidiu com o pico populacional dos ácaros predadores (Costa-Comelles \& Avilla 1992) (Figura 3) e com o pleno desenvolvimento foliar das macieiras, o que possibilitou aceitar níveis maiores para o ácarovermelho, devido à maior tolerância da planta (Fauvel et al. 1993). Neste segundo ano, $55,8 \%$ da área não recebeu acaricida, sendo que as parcelas de Gala foram responsáveis por $59 \%$ das pulverizações (Tabela 3). O menor uso de acaricidas foi em conseqüência do aparecimento natural de $N$. californicus e das liberações de 2.100 .000 e de 3.600.000 ácaros predadores obtidos, respectivamente, na estufa e nas podas verdes. Estas liberações ocorreram, preferencialmente, nas parcelas de macieira com baixa densidade de ácaros predadores ou em áreas que necessitavam estabilizar ambas as populações.

O uso de phosmet, trichlorfon e sumithion para o controle de mosca-das-frutas não apresentou efeito negativo marcante sobre o desenvolvimento de $N$. californicus no pomar, sugerindo que a população foi selecionada, obtendo indivíduos tolerantes, o que é desejável em programas de controle biológico (Rosen \& Huffaker, 1982). Os resultados de toxicidade levaram a eliminar os inseticidas pertencentes à classe dos altamente tóxicos ou utilizá-los com restrição, como foi o caso do fenthion, que foi utilizado somente quando havia mais do que 20 moscasdas-frutas/frasco/dia, fato que ocorreu em parcelas isoladas, principalmente próximas às matas, capoeiras e outros redutos naturais de A. fraterculus (Orth et al. 1986). Fenthion não foi descartado completamente devido à eficiência de sua ação de profundidade (Salles \& Kovaleski 1990b) e à necessidade econômica de manter a qualidade dos frutos. Outro produto de uso com restrição foi azinphos ethyl, recomendado exclusivamente contra E. lanigerum.

Ciclo vegetativo de 1994/95 e 1995/96. As amostragens de ovos de inverno (Tabela 5) e de porcentagem de presença de P. ulmi revelaram populações baixas (Figura 4 e 5) durante estes dois ciclos vegetativos. $N$. californicus acompanhou estas flutuações, mantendo-se em equilíbrio (Figura 4 e 5), o que é desejável para um inimigo natural (Rosen \& Huffaker, 1982). A migração para as ervas daninhas em abril e o ressurgimento natural possibilitaram reduzir em $70 \%$ a produção de ácaros predadores na estufa. Nesses dois ciclos, as liberações ocorreram em certas linhas de plantio, principalmente, em beira de estrada, pois observou-se que 
TABELA 1 - Pomar de macieira das variedades Gala e Fuji, com respectiva área (ha) por parcela e número de subdivisões (quadra), da Agropastoril Rincão das Flores, Vacaria, Rio Grande do Sul.

\begin{tabular}{|c|c|c|c|c|}
\hline Parcela & Variedade & Área (ha) & $\begin{array}{c}\text { Número de } \\
\text { quadras }\end{array}$ & Relevo e vegetação \\
\hline I & $\begin{array}{l}\text { Fuji } \\
\text { Gala }\end{array}$ & $\begin{array}{l}40,8 \\
16,7\end{array}$ & $\begin{array}{l}8 \\
3\end{array}$ & $\begin{array}{l}\text { área ondulada, com vegetação arbórea nativa e com } 2 \text { ha de Pinus no interior } \\
\text { área plana, sem vegetação arbórea no interior }\end{array}$ \\
\hline II & Gala & 59,2 & 13 & $\begin{array}{l}\text { parcela plana, sem vegetação arbórea no interior e com bosques nativos e de Pinus } \\
\text { em duas bordaduras opostas }\end{array}$ \\
\hline III & Gala & 16,6 & 4 & parcela localizada em um vale, com pínus nas partes mais elevadas \\
\hline IV & $\begin{array}{l}\text { Fuji } \\
\text { Gala }\end{array}$ & $\begin{array}{l}26,2 \\
14,8\end{array}$ & $\begin{array}{l}9 \\
2\end{array}$ & $\begin{array}{l}\text { área levemente ondulada, com } 4,5 \text { ha de bosques isolados de Pinus } \\
\text { área inclinada sem vegetação arbórea no interior e com pínus na bordadura }\end{array}$ \\
\hline V & $\begin{array}{l}\text { Fuji } \\
\text { Gala }\end{array}$ & $\begin{array}{l}13,2 \\
10,1\end{array}$ & $\begin{array}{l}8 \\
7\end{array}$ & parcela inclinada, com adundante vegetação arbórea nativa e Pinus entre as quadra \\
\hline VI & $\begin{array}{l}\text { Fuji } \\
\text { Gala }\end{array}$ & $\begin{array}{c}26,5 \\
5\end{array}$ & $\begin{array}{c}12 \\
2\end{array}$ & $\begin{array}{l}\text { área plana, com } 1 \text { ha de vegetação arbórea no interior da área } \\
\text { área plana com mato nativo em uma das bordaduras }\end{array}$ \\
\hline Total & $\begin{array}{l}\text { Gala } \\
\text { Fuji }\end{array}$ & $\begin{array}{l}122,4 \\
106,7\end{array}$ & $\begin{array}{l}31 \\
37\end{array}$ & \\
\hline
\end{tabular}

TABELA 2 - Inseticidas para controle de pragas de macieira das variedades Gala e Fuji. Agropastoril Rincão das Flores, Vacaria-RS.

\begin{tabular}{|c|c|c|c|c|c|c|c|c|c|c|c|c|c|c|c|c|c|}
\hline \multirow{2}{*}{ Ano } & \multirow{2}{*}{ Variedade } & \multicolumn{15}{|c|}{ Data de tratamento ${ }^{1}$} & \multirow{2}{*}{$\begin{array}{c}\text { Total de } \\
\text { pulverizações }\end{array}$} \\
\hline & & 20-out & 3-nov & 10-nov & 17-nov & 1-dez & 8-dez & 14-dez & 21-dez & 29-dez & 5-jan & 14-jan & 21-jan & 28-jan & 9-fev & 17-fev & \\
\hline \multirow[t]{2}{*}{ 1992-93 } & Gala & & $\mathrm{ma}$ & & $\mathrm{ma}$ & ph- $-\mathrm{fe}^{2}$ & & $\mathrm{ph}$ & $\mathrm{fe}$ & $\operatorname{tr}$ & & ph-tr & & & $\mathrm{su}$ & & 8 \\
\hline & Fuji & & $\mathrm{ma}$ & & $\mathrm{ma}$ & $\mathrm{ph}-\mathrm{tr} / \mathrm{fe}^{3}$ & & $\mathrm{ph}$ & $\mathrm{fe}$ & $\operatorname{tr}$ & & ph-tr & & su & su & & 10 \\
\hline \multirow[t]{2}{*}{ 1993-94 } & Gala & $\mathrm{az}$ & & & $\mathrm{ph}$ & $\mathrm{ph}$ & $\mathrm{fe}^{4}$ & $\mathrm{ph} / \mathrm{az}$ & & $\mathrm{ph}$ & & ph & & & & & 7 \\
\hline & Fuji & $\mathrm{az}$ & & & $\mathrm{ph}$ & $\mathrm{ph}$ & $\mathrm{az}$ & $\mathrm{fe}^{4}$ & & $\mathrm{ph}$ & & ph & & di & su & & 9 \\
\hline \multirow[t]{2}{*}{ 1994-95 } & Gala & $\operatorname{tr}$ & & ph & $\mathrm{ph}$ & ph & & su & & $\mathrm{ph}$ & & $\operatorname{tr}$ & & & & & 7 \\
\hline & Fuji & $\operatorname{tr}$ & & ph & $\mathrm{ph}$ & $\mathrm{ph}$ & & su & & $\mathrm{ph}$ & & $\operatorname{tr}$ & & $\mathrm{ph}$ & & & 8 \\
\hline \multirow[t]{2}{*}{ 1995-96 } & Gala & & & & $\mathrm{su}$ & $\operatorname{tr}$ & ph & $\mathrm{ph}$ & & & ph & & & & & & 5 \\
\hline & Fuji & & & & su & $\operatorname{tr}$ & ph & ph & & & ph & & & $\operatorname{tr}$ & & $\mathrm{ph}$ & 7 \\
\hline
\end{tabular}

${ }^{1}$ Cada data equivale a um período de 7 dias

${ }^{2}$ Os inseticidas separados por um traço (-) indicam que a área foi dividida, sendo que o primeiro inseticida foi pulverizado nas parcelas de liberação de Neoseiulus californicus.

${ }^{3}$ Os inseticidas separados por uma barra (/) indicam que a área foi dividida, e cada parte foi pulverizada com um dos inseticidas

${ }^{4}$ Fenthion foi pulverizado em parcelas com mais do que 20 Anastrepha fraterculus/frasco/dia.

$\mathbf{a z}$ - azinphos ethyl; di - dimetoato; fe - fenthion; ma - malathion; ph - phosmet; su - fenitrotion; tr - triclorfon

TABELA 3 - Liberação de Neoseiulus californicus em parcelas de macieira, no ciclo vegetativo de 1992/93. Agropastoril Rincão das Flores, Vacaria, Rio Grande do Sul.

\begin{tabular}{|c|c|c|c|c|c|c|c|}
\hline \multirow{2}{*}{ P a rce la } & \multirow{2}{*}{$\begin{array}{l}\text { Quadras } \\
\text { variedade }\end{array}$} & \multicolumn{5}{|c|}{ Hectares } & \multirow{2}{*}{$\begin{array}{l}\text { Total } \\
(\mathrm{h} a)\end{array}$} \\
\hline & & O u tubro & $\mathrm{Novem} \mathrm{bro}$ & $\mathrm{Dezem}$ bro & Janeiro & Fevereiro & \\
\hline \multirow[t]{2}{*}{$\mathrm{I}$} & $8 \mathrm{Fuji}$ & 0,0 & 6,7 & 3,5 & 18,3 & 12,3 & 40,8 \\
\hline & $3 \mathrm{G}$ a la & 0,0 & 0,0 & 16,7 & 0,0 & 0,0 & 16,7 \\
\hline 11 & $13 \mathrm{G}$ a la & 31,2 & 0,0 & 1,0 & 9,0 & 18,0 & 59,2 \\
\hline 111 & $4 \mathrm{G}$ a Ia & 3,3 & 13,3 & 0,0 & 0,0 & 0,0 & 16,6 \\
\hline \multirow[t]{2}{*}{ IV } & $9 \mathrm{Fuji}$ & 0,0 & 9,4 & 2,7 & 2,2 & 11,9 & 26,2 \\
\hline & $2 \mathrm{G}$ a la & 0,0 & 5,3 & 0,0 & 0,0 & 9,5 & 14,8 \\
\hline \multirow[t]{2}{*}{ V } & $8 F u j i$ & 0,0 & 2,5 & 1,0 & 9,3 & 0,4 & 13,2 \\
\hline & $7 \mathrm{G}$ a la & 1,7 & 5,3 & 0,0 & 0,0 & 3,1 & 10,1 \\
\hline \multirow[t]{2}{*}{ V I } & $12 \mathrm{Fu} \mathrm{ji}$ & 9,1 & 4,1 & 4,0 & 0,0 & 9,3 & 26,5 \\
\hline & $2 \mathrm{G}$ a la & 0,0 & 1,0 & 4,0 & 0,0 & 0,0 & 5,0 \\
\hline Total (ha) & $37 \mathrm{Fu} \mathrm{ji}$ & 9,1 & 22,7 & 11,2 & 29,8 & 33,9 & 106,6 \\
\hline Total (ha) & $31 \mathrm{G}$ a la & 36,2 & 24,9 & 21,7 & 9,0 & 30,6 & 122,4 \\
\hline
\end{tabular}


TABELA 4 - Acaricidas para o controle de Panonychus ulmi em macieira, variedades Gala e Fuji, ciclos vegetativos de 1992/93 e de 1993/94, Agropastoril Rincão das Flores, Vacaria, Rio Grande do Sul.

\begin{tabular}{|c|c|c|c|c|c|c|c|c|c|c|c|c|}
\hline \multirow{2}{*}{ Ano } & \multirow{2}{*}{ Variedade } & \multirow{2}{*}{ Parcela } & \multicolumn{8}{|c|}{ Data de tratamento } & & \multirow{2}{*}{$\begin{array}{l}\text { \% da área } \\
\text { pulverizada }^{2}\end{array}$} \\
\hline & & & 20 -out & 12-nov & 27-nov & $12-\mathrm{dez}$ & $22-\mathrm{dez}$ & 7 -jan & 14-jan & 27 -jan & $10-\mathrm{fev}$ & \\
\hline \multirow[t]{4}{*}{ 1992-93 } & Fuji & I & $\operatorname{cl}(0,6)^{1}$ & $\mathrm{cl}(10,7)$ & & $\operatorname{pr}(13,6)$ & pr (6) & $\operatorname{pr}(11,2)$ & $\operatorname{pr}(6,6)$ & & $\operatorname{pr}(18)$ & 163,3 \\
\hline & & IV & & $\operatorname{pr}(1,1)$ & & $\operatorname{pr}(17,5)$ & $\operatorname{pr}(4,8)$ & $\mathrm{cl}+\operatorname{pr}(16,9)$ & & & $\operatorname{pr}(2,1)$ & 162,0 \\
\hline & & $\mathrm{V}$ & $\mathrm{cl}(1,7)$ & $\operatorname{pr}(1,9)$ & & $\operatorname{pr}(5,6)$ & & $\operatorname{pr}(1,2)$ & & & & 78,8 \\
\hline & & VI & $\operatorname{cl}(7,5)$ & & & $\operatorname{pr}(1,3)$ & & $\operatorname{pr}(7,4)$ & $\mathrm{cl}+\operatorname{pr}(4)$ & & $\operatorname{pr}(1,2)$ & 80,9 \\
\hline \multirow[t]{7}{*}{ Total pulverizado (ha) } & & & 9,8 & 13,7 & & 38 & 10,8 & 36,7 & 10,6 & 0 & 21,3 & 132,1 \\
\hline & Gala & I & & $\mathrm{cl}(2,5)$ & & $\operatorname{pr}(11,6)$ & $\operatorname{pr}(11,8)$ & $\operatorname{pr}(11,6)$ & & & & 221,7 \\
\hline & & II & $\operatorname{cl}(26)$ & $\operatorname{cl}(17,8)$ & & $\operatorname{pr}(43,8)$ & $\operatorname{pr}(43,8)$ & & & & & 222,0 \\
\hline & & III & & $\operatorname{cl}(7,5)$ & & $\operatorname{pr}(13,9)$ & & $\operatorname{pr}(16,6)$ & & & & 229,5 \\
\hline & & IV & & & & & & & & & & 0,0 \\
\hline & & $\mathrm{V}$ & & & & & & & & & & 0,0 \\
\hline & & IV & & & & & $\operatorname{pr}(5,2)$ & $\operatorname{pr}(5,2)$ & & & & 70,3 \\
\hline Total pulverizado (ha) & & & 26 & 27,8 & 0 & 69,3 & 60,8 & 33,4 & & & & 177,5 \\
\hline Hectares pulverizados & & & 35,8 & 41,5 & 0 & 107,3 & 71,6 & 70,1 & 10,6 & 0 & 21,3 & 156,5 \\
\hline \multirow[t]{4}{*}{$1993 / 94$} & Fuji & I & $\operatorname{cl}(11,3)$ & & & & & & & & & 27,7 \\
\hline & & IV & & & & $\operatorname{pr}(8,5)$ & & & & & & 32,5 \\
\hline & & $\mathrm{V}$ & $\operatorname{cl}(6,3)$ & & & & & & & & & 47,7 \\
\hline & & VI & $\mathrm{cl}(4)$ & & & $\operatorname{pr}(11,5)$ & & & & & & 58,6 \\
\hline \multirow[t]{7}{*}{ Total pulverizado (ha) } & & & 21,6 & & & 20 & & & & & & 39,0 \\
\hline & Gala & I & & & & & & & & & & 0,0 \\
\hline & & II & $\mathrm{cl}(50,6)$ & & & & & & & & & 85,5 \\
\hline & & III & & & & $\operatorname{pr}(9)$ & & & & & & 54,3 \\
\hline & & IV & & & & & & & & & & 0,0 \\
\hline & & $\mathrm{V}$ & & & & & & & & & & 0,0 \\
\hline & & VI & & & & & & & & & & 0,0 \\
\hline Total pulverizado (ha) & & & 50,6 & & & 9 & & & & & & 48,7 \\
\hline Hectares pulverizados & ha) & & 72,2 & 0 & 0 & 29 & 0 & 0 & 0 & 0 & 0 & 62,4 \\
\hline
\end{tabular}

${ }^{1} \mathrm{O}$ valor entre parênteses indica o número de hectares pulverizados em cada parcela e data.

2 Porcentagem da área pulverizada em relação à área total de cada parcela

cl - clofentezine; pr - propargite.

A Neoseiulus californicus em Gala

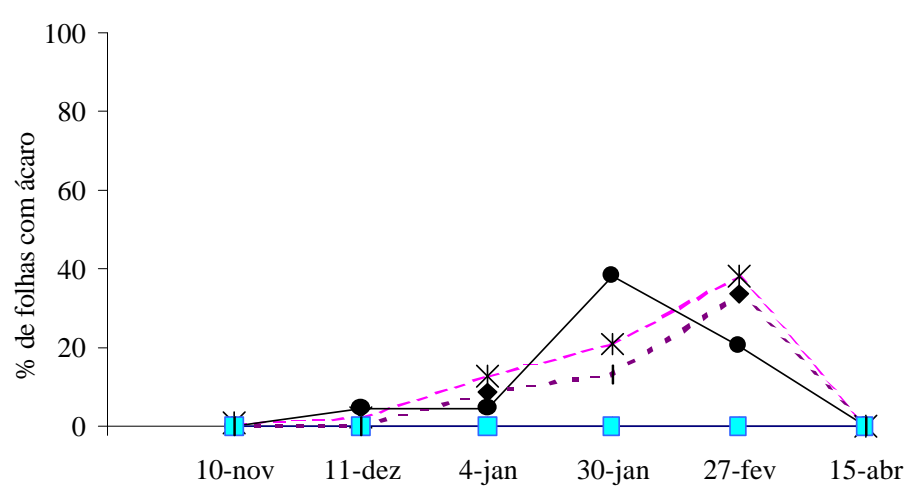

C

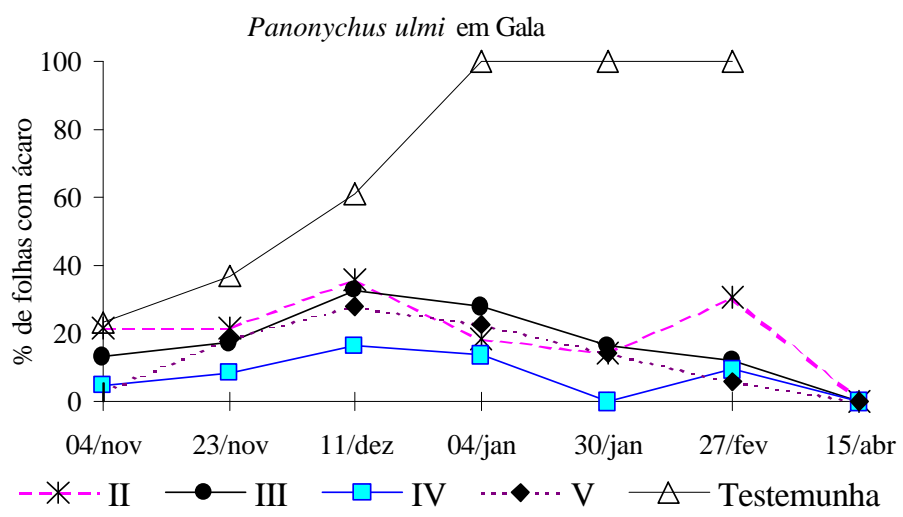

B Neoseiulus californicus em Fuji



D

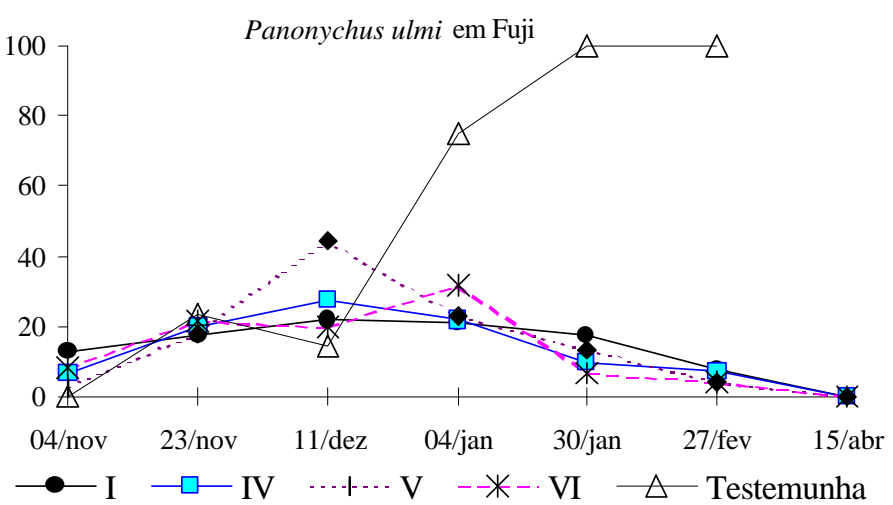

FIGURA 1 - Flutuação populacional média de Neoseiulus californicus e Panonychus ulmi em parcelas de macieira, incluindo testemunha sem tratamento, nas variedades Gala e Fuji, no ciclo vegetativo de 1992/93. Agropastoril Rincão das Flores, Vacaria, RS. 
TABELA 5 - Ovos de inverno de Panonychus ulmi em ramos de macieiras, coletados antes e depois da quebra de dormência com óleo mineral, durante três ciclos vegetativos. Agropastoril Rincão das Flores, Vacaria-RS.

$1992 / 93$

\begin{tabular}{|c|c|c|c|c|c|}
\hline \multirow{3}{*}{ Parcela } & \multicolumn{4}{|c|}{ Ramos amostradose média de ovos por gema } & \multirow{3}{*}{$\begin{array}{c}\text { Redução de ovos } \\
\text { inverno após óleo } \\
\text { mineral }(\%)\end{array}$} \\
\hline & \multicolumn{2}{|c|}{ antes do óleo mineral* } & \multicolumn{2}{|c|}{ depois do óleo mineral** } & \\
\hline & $\mathrm{n}^{\circ} \mathrm{ramos}$ & ovos & $\mathrm{n}^{\circ} \mathrm{ramos}$ & ovos & \\
\hline I & 795 & $1,0 \mathrm{C}$ & 840 & $0,6 \mathrm{C}$ & 40 \\
\hline II & 1035 & $1,0 \mathrm{C}$ & 1140 & $0,1 \mathrm{C}$ & 90 \\
\hline III & 315 & $1,3 \mathrm{C}$ & 375 & $0,3 \mathrm{C}$ & 77 \\
\hline IV & 735 & $1,4 \mathrm{C}$ & 855 & $0,2 \mathrm{C}$ & 85 \\
\hline $\mathrm{V}$ & 1020 & $1,7 \mathrm{C}$ & 915 & $0,6 \mathrm{C}$ & 64 \\
\hline V I & 960 & $1,9 \mathrm{C}$ & 915 & $0,7 \mathrm{C}$ & 63 \\
\hline \multicolumn{6}{|c|}{ Testemunhas } \\
\hline G a la & 45 & $85,7 \mathrm{~A}$ & 45 & $25,3 \mathrm{~A}$ & 70 \\
\hline $\mathrm{Fuji}$ & 45 & $33,9 \mathrm{~B}$ & 45 & $15,0 \mathrm{~B}$ & 56 \\
\hline
\end{tabular}

*-realizado em 10-08-1993

** - realizado em 27-09-1993

$1993 / 94$

\begin{tabular}{|c|c|c|c|c|c|}
\hline \multirow{3}{*}{$\mathrm{P}$ a rce la } & \multicolumn{4}{|c|}{ Ramos amostrados e média de ovos por gema } & \multirow{3}{*}{$\begin{array}{c}\text { Redução de ovos } \\
\text { inverno após óleo } \\
\text { mineral (\%) }\end{array}$} \\
\hline & \multicolumn{2}{|c|}{ antes do óleo mineral* } & \multicolumn{2}{|c|}{ depois do óleo mineral** } & \\
\hline & $\mathrm{n}^{\circ}$ ramos & ovos & $\mathrm{n}^{\circ} \mathrm{ramos}$ & ovos & \\
\hline I & 1335 & $2,4 \mathrm{~B}$ & 1275 & $0,1 \mathrm{~A}$ & 95 \\
\hline II & 1665 & $0,4 \mathrm{~B}$ & 1395 & $0,3 \mathrm{~A}$ & 25 \\
\hline III & 480 & $1,2 \mathrm{~B}$ & 300 & $0,1 \mathrm{~A}$ & 92 \\
\hline IV & 1695 & $5,4 \mathrm{~A}$ & 1215 & $0,4 \mathrm{~A}$ & 92 \\
\hline $\mathrm{V}$ & 1335 & $0,3 \mathrm{~B}$ & 1050 & $0,2 \mathrm{~A}$ & 33 \\
\hline V I & 1380 & $0,6 \mathrm{~B}$ & 1095 & $0,4 \mathrm{~A}$ & 33 \\
\hline
\end{tabular}

* realizado em 10-08-1994

** - realizado em 23-09-1994

$1995 / 96$

\begin{tabular}{ccc}
\hline \multirow{2}{*}{ Parcela } & Ramosamostrados e média de ovos \\
\cline { 2 - 3 } & antes do óleo mineral* \\
\cline { 2 - 3 } n $^{\text {o ramos }}$ & ovos \\
\hline I & 1275 & $0,1 \mathrm{~A}$ \\
II & 1395 & $0,3 \mathrm{~A}$ \\
III & 300 & $0,1 \mathrm{~A}$ \\
IV & 1215 & $0,4 \mathrm{~A}$ \\
V & 1050 & $0,2 \mathrm{~A}$ \\
V I & 1095 & $0,4 \mathrm{~A}$
\end{tabular}

* - realizado em 11-08-1995

M édias seguidas pela mesma letra, na coluna, não diferem siginificativamente,

a o nívelde $5 \%$, segundo o teste de Duncan.
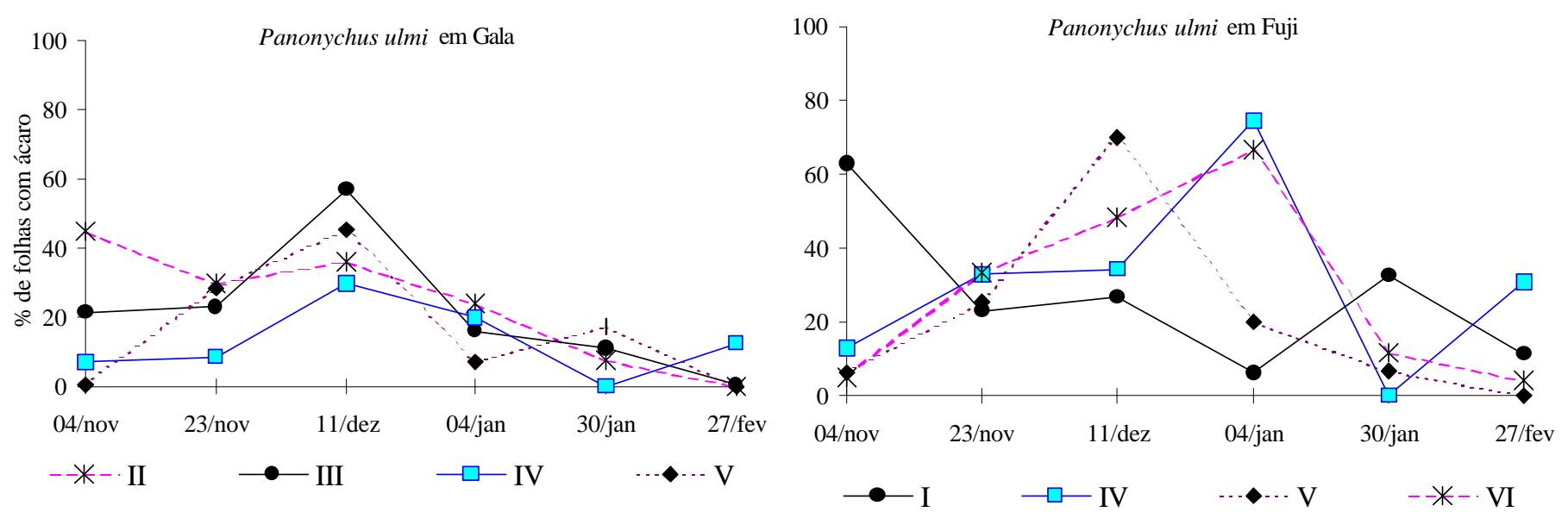

FIGURA 2 - Flutuação populacional de Panonychus ulmi nas quadras de macieira que apresentaram maior presença do ácarovermelho, nas variedades Gala e Fuji e no ciclo vegetativo de 1992/93. Agropastoril Rincão das Flores, Vacaria-RS. 

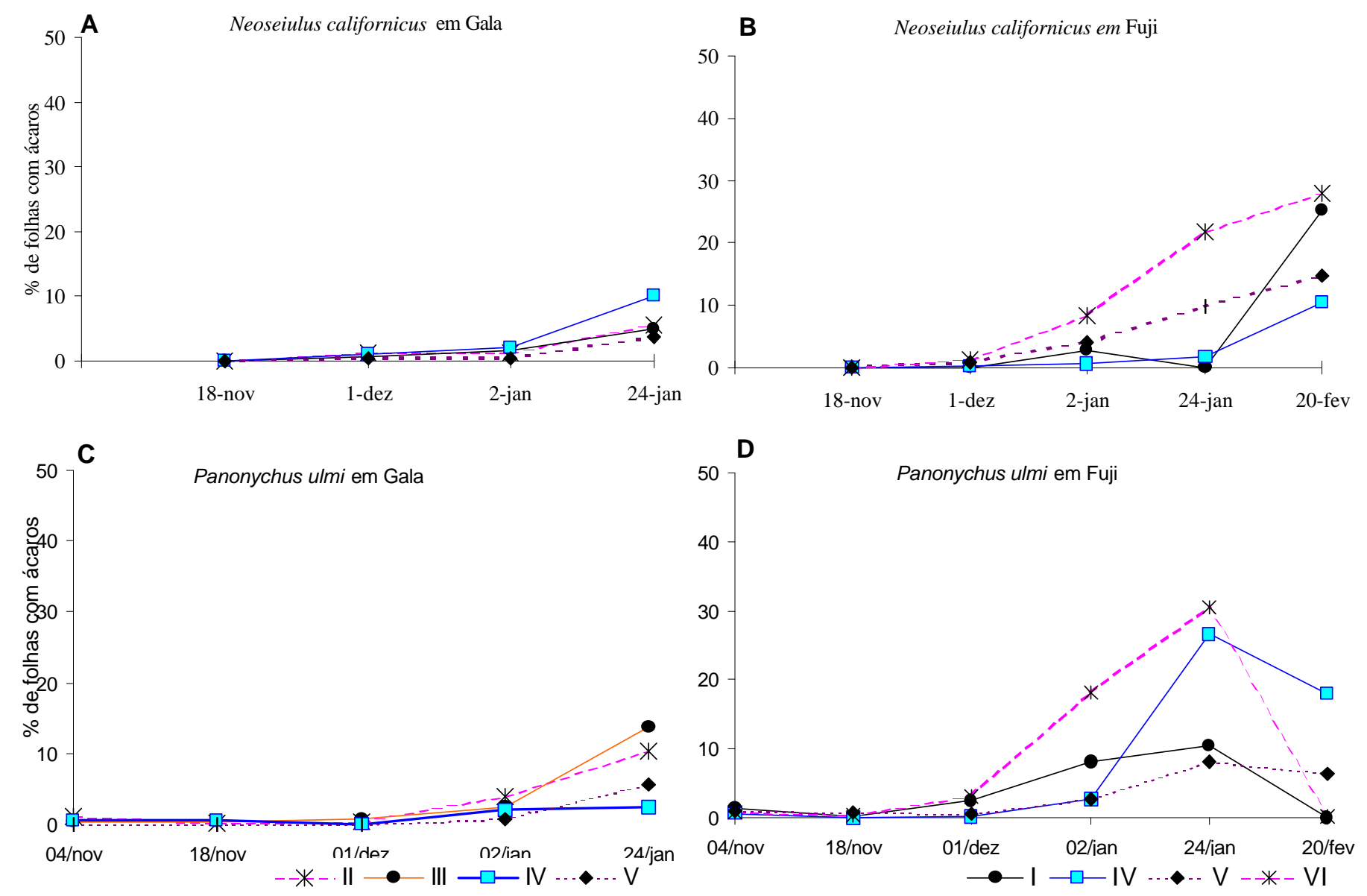

FIGURA 3 - Flutuação populacional de Neoseiulus californicus e Panonychus ulmi em parcelas de macieira, nas variedades Gala e Fuji, no ciclo vegetativo de 1993/94. Agropastoril Rincão das Flores, Vacaria-RS.
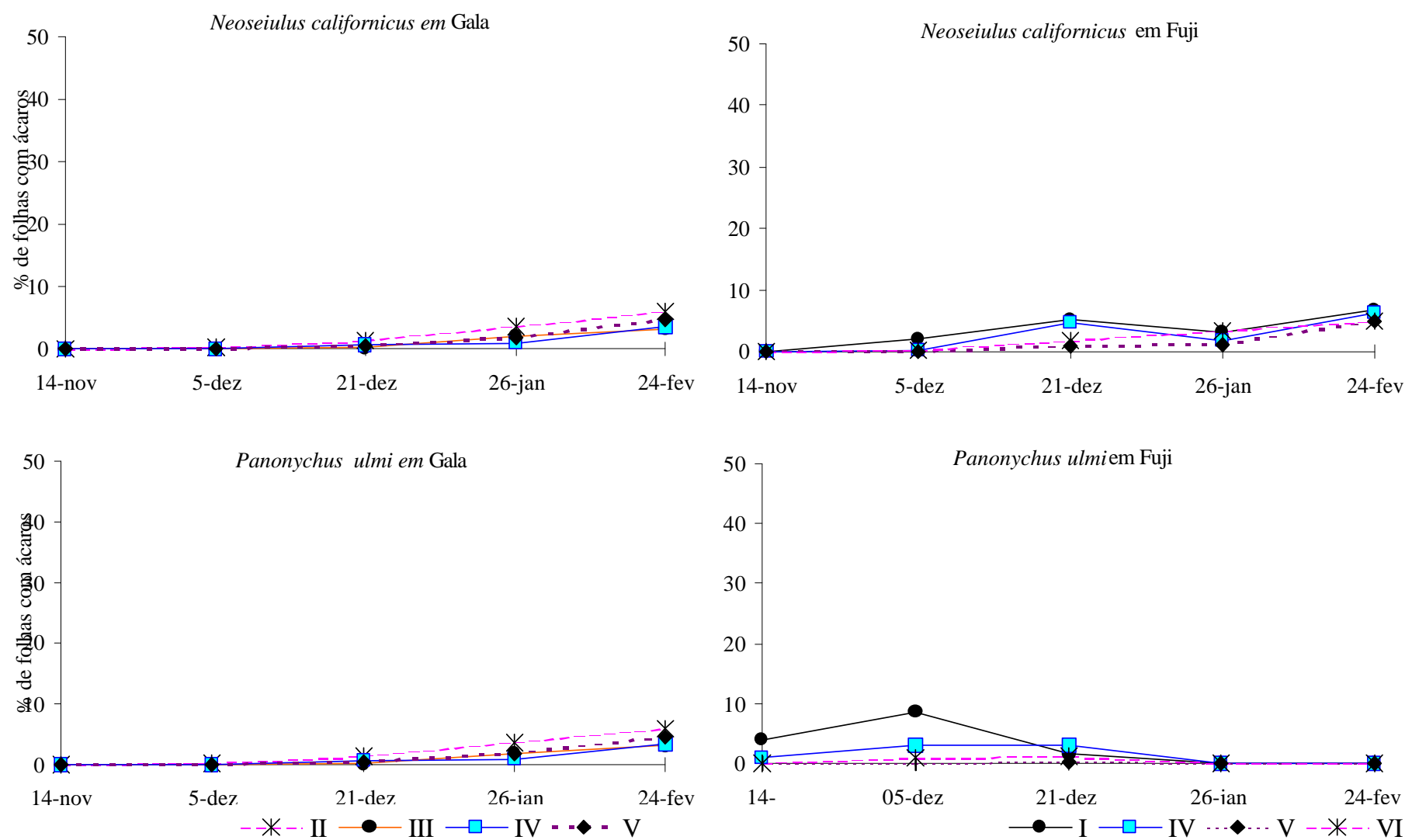

FIGURA 4 - Flutuação populacional de Neoseiulus californicus e Panonychus ulmi em parcelas de macieira, nas variedades Gala e Fuji, no ciclo vegetativo 1994/95. Agropastoril Rincão das Flores, Vacaria-RS. 

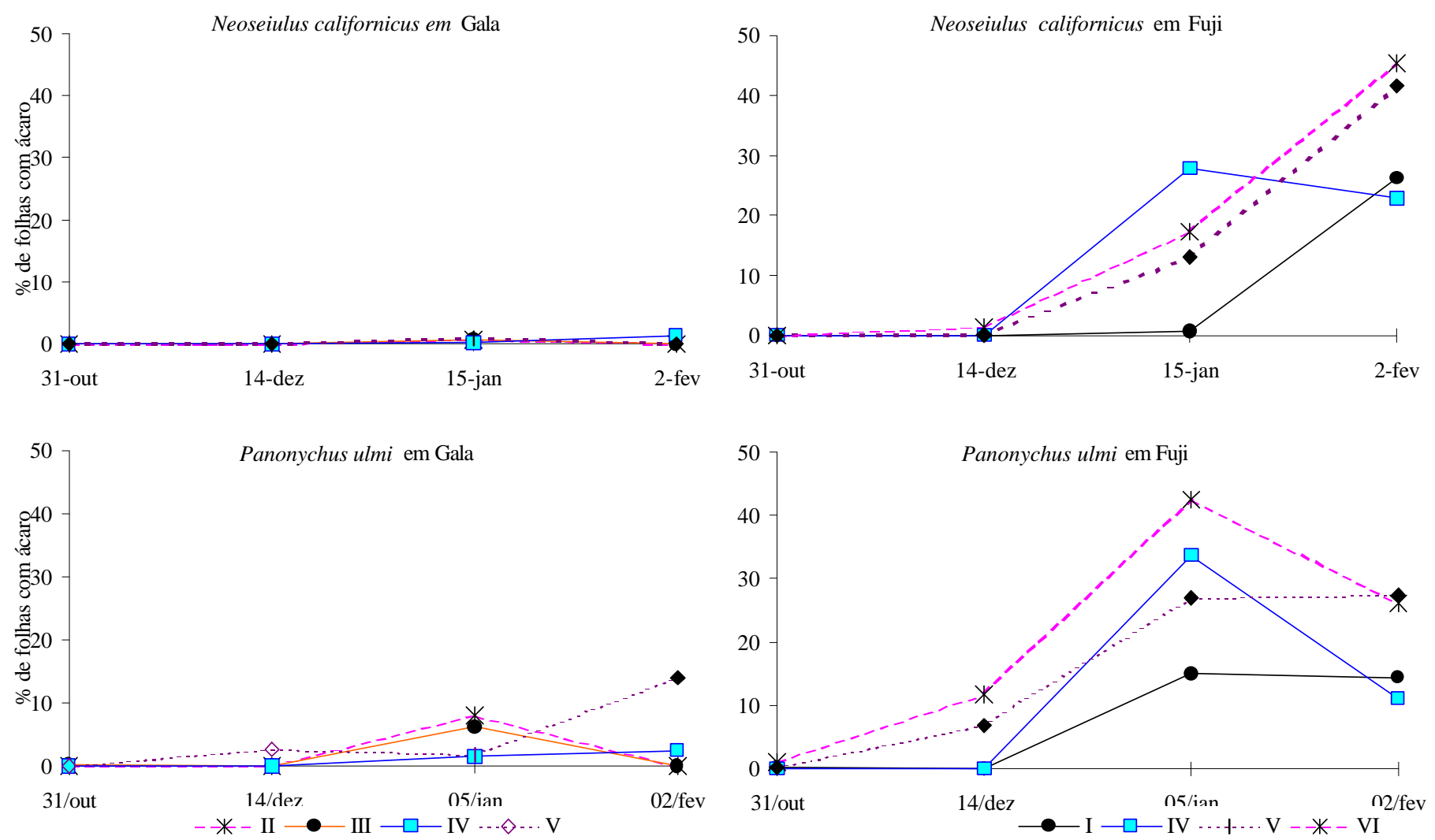

FIGURA 5 - Flutuação populacional de Neoseiulus californicus e Panonychus ulmi em parcelas de macieira, nas variedades Gala e Fuji, no ciclo vegetativo 1995/96. Agropastoril Rincão das Flores, Vacaria-RS.

os ácaros-vermelhos se desenvolvem melhor nas bordaduras do que no interior das quadras (Monteiro, informação pessoal), provavelmente, devido ao estresse hídrico que a poeira das folhas promove sobre a fisiologia das macieiras (Specht 1965, Wermelinger et al. 1990; Monteiro \& Fauvel, 1996).

As maiores dificuldades para a implantação do controle biológico de ácaros ocorreram nos dois primeiros anos, em função da restruturação das práticas fitossanitárias realizadas no pomar. Os agroquímicos foram selecionados a partir da eficiência do controle de artrópodos e da toxicidade em relação aos inimigos naturais. A manutenção dos ácaros predadores no pomar, por meio de liberações inundativas, foi uma estratégia correta, permitindo o equilíbrio entre as duas espécies em áreas de baixa densidade de ácaros predadores, de maneira que o controle biológico de $P$. ulmi foi possível a partir do segundo ano. A adaptação de $N$. californicus às condições climáticas e culturais do pomar foram manifestadas pela capacidade de ressurgência natural, nos anos posteriores à liberação, sugerindo que o predador sobreviveu durante o inverno, utilizando outras fontes de alimento. $N$. californicus dirigiu-se para as ervas daninhas quando houve redução de $P$. ulmi nas folhas de macieira; abrem-se perspectivas de novos estudos para demonstrar a importância do manejo de ervas daninhas na sobrevivência de $N$. californicus durante o inverno

\section{AGRADECIMENTOS}

Ao Ilmo. Sr. Leandro Kolodny, diretor da Agropastoril
Rincão das Flores Ltda., pelo financiamento deste projeto, e ao técnico Omilton Capelini, pela ajuda na sua realização. Ao Dr. José Fernando da S. Protas (CNPUV) e Dr. Gilberto de Moraes (CNPMA), pelo apoio à execução deste trabalho.

\section{REFERÊNCIAS BIBLIOGRÁFICAS}

AUDEMARD, H.; BAGGIOLINI, M.; AMARO, P., LOURDES BORGES, M.; BASSINO, J. P., BENASSY, C.; LAVADINHO, A. M. P.; BRADER, L.; MILAIRE, H. G., MAGALHÃES SILVA, G.. Introdução à proteção integrada. Lisboa: Ramos, Afonso \& Moita, 1982. 276p.

ANDREI, E. Compêndio de defensivos agrícolas. 3. ed. São Paulo: Andrei, 1990.478p.

ASSOCIATION NATIONALE POUR LA PROTECTION DES PLANTES. Les actions secondaires des produits phytosanitaires. Paris: Association Nationale pour la Protection des Plantes, 1987. v. 4: 60p.

BAGGIOLINI, M.; GUIGNARD, E. Etude du comportement des acariens en fonction du programme de traitements adopté dans les vergers. OEPP, Paris, v. 52, p. 17-32, 1969.

BAKKER, F. M.; GROVE, A.; BLÜMEL, S.; CALIS J.; OOMEN, $P$. Side-effect test for phytoseiids and their rearing methods. IOBC/WPRS Bulletin, Montfavet, v. 15, p. 61-81, 1992. 
BAILLOD, M. La technique et l'utilité du contrôle d'hiver des pontes de l'araignée rouge $(P$. ulmi) sur bois de taille en arboriculture fruitière. Revue Suisse Viticulture Arboriculture Horticulture, Lausanne, v. 11, p. 89-92, 1979.

BAILLOD, M.; SCHLAEPFER, R. Simplification des contrôles par utilisation de l'échantillonage séquentiel pour l'acarien rouge (viticulture et arboriculture). La défense des végétaux, Paris, v. 214, p. 71-85, 1982.

BAILLOD, M. Lutte biologique contre les acariens phytophages Revue Suisse Viticulture Arboriculture Horticulture, Lausanne, v. 16,p. 137-142, 1984.

BAILLOD, M.; GUIGNARD, E., MISCHLER M.; VAUTIER, PH. Contrôle des oeufs de l'acariens rouge (Panonychus ulmi Koch) sur bois de taille en viticulture et prévision du risque. Revue Suisse Viticulture Arboriculture Horticulture, Lausanne, v. 21, p. 7-14, 1989.

BESSON, J.; JOLY, E.; TOUZEAU, J.. Les actions secondaires des antiparasitaires agricoles. Phytoma, Paris, v. 296, p.18-26, 1978.

BLEICHER, J.; GASSEN, D. N.; RIBEIRO, L. G.; TANAKA, H., ORTH, A. I.. A mosca-das-frutas em macieira e pessegueiro. Florianópolis: EMPASC, 1982. 28p. (Boletim Técnico 19).

BLOMMERS, L. La lutte integrée et la maitrise naturelle des populations d'acariens phytophages en vergers de pommiers aux Pays-Bas. In: COLLOQUE SUR LES ACARIENS DES CULTURES, 1989, Montpellier, Anais.... v. 2, p. 489-499.

BOSTANIAN, N. J.; COULOMBE, L. J. An integrated pest management program for apple orchards in Southwestern Quebec. Canadian Entomologist, Ottawa, v. 118, p. 1131-1142, 1986.

COSTA-COMELLES, J.; AVILLA, J. Estrategia de control biológico del ácaro rojo de los frutales (Panonychus ulmi (Koch)) en um programa de control integrado de plagas del manzano. Phytoma, Paris, v. 40, p. 40-52, 1992.

CROFT, B. A.; HOYT, S. C. Integrated management of insect pests of pome and stone fruits. New York: John Wiley and Sons, 1983.p. 456.

DEGRANGE, M. H. Mode d'action de la clofentézine et efficacité de différentes acaricides à forte tension de vapeur sur des oeufs de Panonychus ulmi Koch. 1987. 40f. Dissertação (Mestrado) Université Sciences Techniques du Lanquedoc, Montpellier, 1987.

DE BUSSCHÈRE, P. J. Distribution des formes hivernantes des ravageurs du pommier dans la région de Gembloux (novembre et décembre 1967). Bulletin Recherche Agronomique, Gembloux, v. 1-2, p. 152-176, 1970.

FAUVEL, G.; ATGER, P. Etude de l'évolution des insectes auxiliaires et de leurs relation avec le psille du poirier ( Psylla pyri L.) et l'acarien rouge (Panonychus ulmi Koch) dans deux vergers du Sud-Est de la France en 1979. Agronomie, Paris, v. 1, p. 813-
$820,1981$.

FAUVEL, G.; BOURGOUIN, B.; PERRON, G.; ROUZET, J. Importance de la colonisation des vergers de pommier et pécher du sud de la France par Neoseiulus californicus (McGregor) et conséquences pour la lutte biologique contre l'araignee rouge Panonychus ulmi (Koch) (Acari: Phytoseiidae, Tetranychidae). In: CONFÉRENCE INTERNATIONALE RAVAGERS EN AGRICULTURE, 3., 1993, Montpellier, 1993. Anais..., v. 2, p. 587596.

HOY, M. A. Genetic improvement of insects: fact or fantasy. Environmental Entomology, Steeles Tavern, v. 5, p. 833-839, 1976.

HOY, M. A. Aerial dispersal and field efficacy of a genetically improved of the spider mite predator Metaseiulus occidentalis, Acarina, Phytoseiidae. Entomologia experimentalis et applicata, Dordrecht, v. 32, p. 205-212, 1982.

HUFFAKER, C. B.; VRIE, M. VAN DE; MCMURTRY, J. A. The ecology of tetranychid mites and their natural control. Annual Review of Entomology, New York, v. 14, p. 125-174, 1969.

HUFFAKER, C. B.; LUCK, R. F.; MESSENGER, P.S. The ecological basis of biological control. In: INTERNATIONAL CONGRESS OF ENTOMOLOGY, 15., 1977, Washington D. C. Anais..., p. 560-586.

JEPPSON, L. R.; KEIFER, H. H.; BAKER, E. W. Mites injurious to economic plants. Berkeley, Los Angeles: University of California Press, 1975. 614p.

MATHYS, G.; BAGGIOLINI, M. Étude de la valeur pratique des méthodes de lutte intégrée dans les cultures fruitières. Agriculture Romande, Lausanne, v. 6, p. 27-50, 1967.

MONTEIRO, L. B. Controle biologique de Panonychus ulmi (Koch) (Acari: Tetranychidae) en fonction du programme de traitement contre la mouche des fruits dans la région de Vacaria (Brésil). In: CONFÉRENCE INTERNATIONALERAVAGERS EN AGRICULTURE, 3., 1993, Montpellier, Anais..., v. 2, p. 611-619.

MONTEIRO, L. B. Tolerância de populações de ovos de inverno e de verão de Panonychus ulmi (Koch) ao ovicida clofentezine, no sudeste e no sudoeste da França. Anais Sociedade Entomológica, Londrina, v. 23, p. 461-466, 1994.

MONTEIRO, L.B.; FAUVEL, G. Influence of three irrigation levels on the reprodution of European red mite Panonychus ulmi Koch and on some biochemical characteristics of leaves of potted apple plants. Anais Sociedade Entomológica, Londrina, v. 25, p. 13-19, 1996.

MONTEIRO, L. B. Criação de ácaros fitófagos e predadores: um caso de produção de Neoseiulus californicus em produtores de maçã. In: PARRA; CORREA-FERREIRA; BOTELHO (Ed) Controle biológico no Brasil: parasitóides e predadores. 2001a. no prelo.

Rev. Bras. Frutic., Jaboticabal - SP, v. 24, n. 2, p. 395-405, agosto 2002 
MONTEIRO, L. B. Seletividade de inseticidas a Neoseiulus californicus McGregor (Acari: Phytoseiidae) em macieira, no Rio Grande do Sul. Revista Brasileira Fruticultura, Jaboticabal, 2001b. no prelo.

MCMURTRY, J. A.; HUFFAKER, C. B.; VAN DE VRIE, M. Ecology of tetranychid mites and their natural enemies: A review. I. Tetranychid enemies: their biological characters and the impact of spray practices. Hilgardia, Berkeley, v. 40, p. 331-390, 1970.

ORTH, A. I.; RIBEIRO, L. G.; REIS FILHO, W. Manejo de pragas. In: EMPASC (Ed.) Manual da cultura da macieira, Florianópolis, 1986.562p.

REIS FILHO, W.; PETRI, J. L. Efeito de tratamentos para a quebra de dormência em macieira no controle do ácaro vermelho europeu. Agropecuária Catarinense, Florianópolis, v. 5, p. 35-37. 1992.

ROSEN, D.; HUFFAKER, C. B. An overview of desired attributes of effective biological control agents, with particular emphasis on mites; In: HOY, M. A.; CUNNINGHAM, G. L.; KNOUTSON, L. (Ed.), Biological control of pests by mites, Berkeley, 1982. $185 \mathrm{p}$.

SALLES, L. A. B.; KOVALESKI, A. Mosca-das-frutas em macieira e pessegueiro no Rio Grande do Sul. HortSul, Pelotas, v. 1, p. 5-9. 1990a.
SALLES, L. A. B., KOVALESKI, A. Inseticidas para o controle da mosca-das-frutas. HortSul, Pelotas, v. 1, p. 10-11, 1990b

SALLES, L. A. B. Mosca das frutas (Anastrepha spp.): Bioecologia e controle. Pelotas: EMBRAPA-CNPFT, 1991. 16p. (Documento 41).

SPECHT, H. B. Effect to water-stress on the reproduction of European red mite Panonychus ulmi (Koch) on young apple trees. Canadian Entomologist, Ottawa, v. 97, p. 82-85, 1965.

SERVICE DE LA PROTECTION DES VÉGÉTAUX Les actions secondaires des produits phytosanitaires. Paris: SPV, 1983.96p.

STAÜBLI, A.; BAILLOD, M., CHARMILLOT, P.-J.; GUIGNARD, E. Le point sur la lutte contre certains ravageurs importants en vergers. Revue Suisse Viticulture Arboriculture Horticulture, Lausanne, v. 23, p. 17-24, 1991.

TIXIER, M.-S.; SERGE, K.; PHILIPPE, A.; WEBER, M. Colonization of languedoc vineyards by phytoseiid mites (Acari: Phytoseiidae): influence of wind and crop environment. Experimental Applied Acarology, Amsterdam, v. 22, p. 523-542, 1998.

WERMELINGER, B.; SCHNIDER, F.; OERTLI, J.J.; BAUMGÄRTNER, J.. Environmental factors affecting the life tables of Tetranychus urticae Koch (Acarina). II. Host plant water stress. Bulletin Société Entomologique Suisse, Lausanne, v. 63, p. 347-357, 1990. 